\title{
O registro geológico da atividade antropogênica na região do Valo Grande, Estado de São Paulo, Brasil
}

\author{
The geological record of anthropogenic activity in the region of Valo \\ Grande, state of São Paulo, Brazil
}

\author{
Diana Melo Italiani $^{\text {ab }}$, Michel Michaelovitch Mahiques ${ }^{\text {ac }}$ \\ ${ }^{a}$ Instituto Oceanográfico, Universidade de São Paulo \\ bdianajgd@gmail.com, cmahiques@gmail.com
}

\begin{abstract}
RESUMO
Após a abertura do canal artificial do Valo Grande, na primeira metade do século XIX, a região do Sistema Estuarino-Lagunar de Cananéia-Iguape, denominada Mar Pequeno, vem sendo influenciada por um intenso processo de assoreamento que mudou, numa curta escala de tempo, a morfologia e sedimentação do local, com a consequente formação de um delta intralagunar antropogênico. Essas evidências foram abordadas e analisadas neste trabalho por meio da elaboração de modelos digitais de terreno, realizados a partir de dados batimétricos obtidos em campo. Além disso, com a elaboração de mapas vetoriais realizados a partir da digitalização da linha de costa de imagens de satélite e mapas topográficos, foi possível fazer um estudo da mudança geomorfológica da linha de costa. O processo de erosão do Valo Grande foi demonstrado através de comparações das seções de perfis batimétricos efetivadas nos anos de 1891 e 1907 pela Comissão Geográfica e Geológica do Estado de São Paulo e dos perfis adquiridos em campo no ano de 2008, com a finalidade de obter a variação da largura e da profundidade do canal ao longo desses anos.
\end{abstract}

Palavras-chave: Sedimentação; Georreferenciamento; Delta; Valo Grande.

\begin{abstract}
After the opening of the Valo Grande artificial channel, during the first half of the XIX century the region of Cananéia-Iguape Estuarine-Lagoon system named Mar Pequeno has being influenced by a strong process of siltation that changed, in a short time scale, the morphology and sedimentation of the site, culminating with the formation of an intralagoonal anthropogenic delta. These evidences were assessed and analyzed in this work through the elaboration of a Digital Elevation Model from batimetric data got in field. Besides, with the elaboration of vetorial maps, which was performed through the digitalization of satellite image of coast lines and topographic maps, it was possible to make a study of the geomorphologic changes of the coastline. The process of erosion at Valo Grande was demonstrated with comparisons of topographic data obtained between 1891 and 1907 and the topographic data obtained in 2008 with the aim of acquiring the width and depth variation of the channel throughout these years.
\end{abstract}

Keywords: Sedimentation; Georeferencing; Delta; Valo Grande.

\section{Introdução}

O crescimento populacional intensificado nas áreas costeiras tem causado maior interesse científico e técnico sobre esses ambientes, com o foco na ordenação do uso e ocupação do solo.

Os estuários estão entre os ambientes mais sensíveis às atividades humanas, uma vez que os processos de erosão e deposição sedimentar influenciam nas variações de topografia de fundo e nas formas sedimentares das margens e canais destes sistemas. As classificações dos estuários variam desde os clássicos estuários de ria até os estuários de barreira. Estes últimos possuem sistemas lagunares associados e comunicação restrita com o oceano, que limita a troca de sedimentos fazendo com que o sistema seja uma área importante de retenção dos mesmos.
As lagunas são definidas por Kjerfve \& Magill (1989) como sendo "ambientes costeiros interiores usualmente orientados paralelamente à costa, separados do oceano por uma barreira, conectados ao oceano por uma ou mais aberturas restritas e possuem profundidades que, às vezes, excedem alguns metros.” Kjerfve \& Magill (1989) ainda afirmaram em seus estudos que as flutuações holocênicas do nível relativo médio do mar acabaram originando esses sistemas lagunares, através da formação de barreiras. A amplitude de maré é um dos fatores condicionantes à existência das lagunas costeiras. Elas só ocorrem em ambientes de micromaré e mesomaré, não ocorrendo em ambientes de macromaré, devido à alta energia das correntes de maré, que têm o poder de dispersar os sedimentos, responsáveis pela construção ou formação da restinga arenosa (Silva et al. 2004). O 
comportamento dos sedimentos nessas áreas é determinado pela energia derivada dos processos associados ao aporte fluvial, à ação da maré e às componentes meteorológicas. Por sua vez, os processos sedimentares influenciam nas variações de topografia de fundo e da linha de costa.

Alguns estuários em regiões de intensa sedimentação fluvial podem acabar sendo preenchidos por sedimentos, podendo evoluir para depósitos deltaicos. As condições hidrodinâmicas dentro de uma laguna costeira, bem como a disponibilidade de sedimentos, são alguns dos mais importantes fatores que controlam as fácies sedimentares dos depósitos lagunares.

Galloway (1975) propôs um sistema de classificação para os deltas, que resulta em três tipos extremos: deltas dominados por rios, dominados por marés e deltas dominados por ondas. Porém, a maioria dos deltas apresenta as três características, com influência de mais de um processo construtivo e destrutivo.

Analisando as variações geomorfológicas de margens e topografia de fundo, através da digitalização de linhas de costa em mapas topográficos e imagens de satélite, além do tratamento de dados batimétricos de diferentes épocas, é possível avaliar a influência dos processos hidrodinâmicos e da ação do homem nas feições sedimentares. Sendo assim, no presente trabalho, foi realizado tratamento de dados batimétricos e geográficos com a finalidade de obter a variação espaço-temporal das características geomorfológicas ocorridas no Sistema Estuarino-Lagunar de CananeiaIguape, devido à abertura do Valo Grande.

\section{2. Área de estudo}

O Sistema Estuarino-Lagunar de Cananeia-Iguape (figura 1) está localizado no litoral sul do estado de São Paulo, entre as latitudes sul $24^{\circ} 40^{\prime}$ e $25^{\circ} 05^{\prime}$ e as longitudes oeste $47^{\circ} 25^{\prime}$ e $48^{\circ} 10^{\prime}$. É É considerado o principal sistema estuarino-lagunar do litoral paulista e, juntamente com Vale do Rio Ribeira de Iguape, forma a maior área de planície costeira do estado de São Paulo.

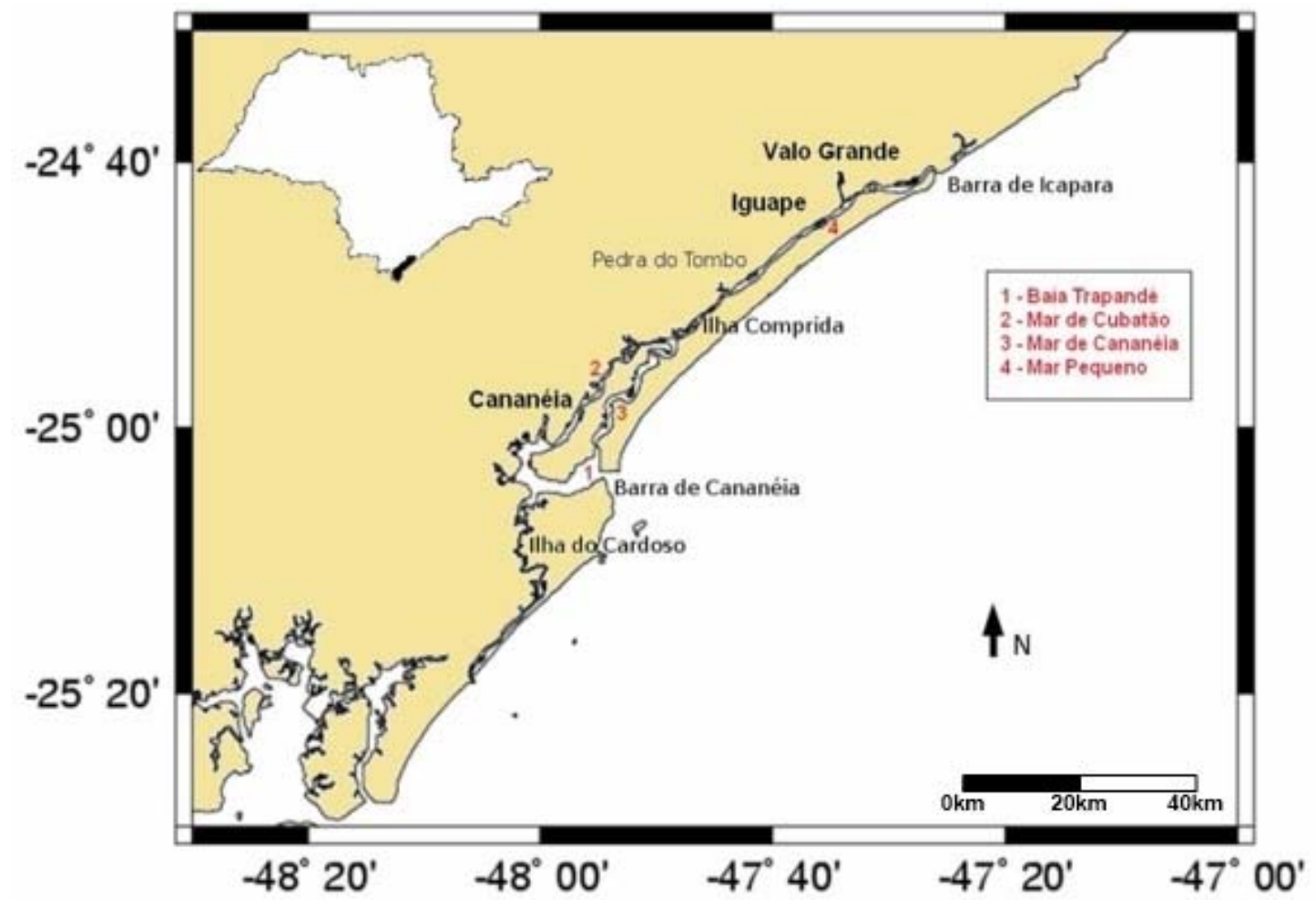

Figura 1: Sistema Estuarino-Lagunar de Cananeia-Iguape, São Paulo. Adaptado de Alves (2009)

Dentro desse sistema encontram-se quatro corpos lagunares, sendo o Mar Pequeno um deles, o qual é fortemente influenciado pela desembocadura do canal artificial do Valo Grande. Este sistema é separado do oceano pela ilha Comprida, e suas ligações com o mar aberto situam-se na barra de Icapara ao norte e na barra de Cananeia ao sul.

A propagação de onda de maré é o principal processo responsável pela circulação hidrodinâmica do sistema, promovendo as misturas entre as águas oceânicas e estuarinas (Bonetti Filho et. al. 1996).
O rio Ribeira de Iguape é o maior curso fluvial do litoral paulista (Geobrás 1966). Tem sua nascente localizada na parte leste da serra de Paranapiacaba em altitudes superiores a $1.000 \mathrm{~m}$. Após um percurso de aproximadamente $470 \mathrm{~km}$, deságua no oceano Atlântico pela barra do Ribeira ao norte da cidade de Iguape. A partir da abertura do canal do Valo Grande, aproximadamente $70 \%$ de seu fluxo foi desviado para o Mar Pequeno, descarregando grande parte do seu material nas águas lagunares (Geobrás 1966). Seu fluxo, que atravessa o canal e desemboca no Mar 
Pequeno, continua, até os dias de hoje, modificando as características geomorfológicas e ecológicas da região.

O canal do Valo Grande tinha por finalidade facilitar o acesso ao porto de Iguape através do rio Ribeira. Porém, o equilíbrio do sistema foi afetado diretamente pela abertura do canal. Com o passar dos anos, o porto tornou-se inacessível e foi desativado, devido ao processo de assoreamento acelerado associado à abertura do canal artificial.

Antes da abertura deste canal, a descarga fluvial da laguna era mínima, e, segundo relatos e mapas da época, as profundidades médias eram de $10 \mathrm{~m}$, com forte influência marinha através das correntes de maré pela provável inexistência de baixios (Teles 1997).

O canal foi aberto entre 1827 e 1852 com largura e profundidade iniciais de 4 e $2 \mathrm{~m}$, respectivamente, e com o passar dos anos sofreu erosão contínua. Em 1889, houve uma tentativa de fechar o Valo Grande no local em que recebia toda a força das águas do rio Ribeira. Porém, quando foi verificado que o método não seria eficaz, suspenderam-se os serviços quando a barragem de pedras estava quase concluída, faltando apenas 1m para atingir o nível d'água nas marés mais baixas.

Por volta de 1850, "pequenos navios de cabotagem" atracavam no Mar Pequeno, em frente a Iguape, enquanto que em 1896 essas embarcações já eram obrigadas a fundear a 600m do cais (Campos 1896). Segundo esse autor, já nessa época observava-se a possível formação de um delta na desembocadura, à medida que o fluxo de água perdia velocidade em função do "aumento da seção e, encontrando as correntes de maré, depositava ali os detritos que trazia em suspensão”. Segundo Geobrás (1966), a partir de 1860 os problemas deixaram de ser o desbarrancamento e o assoreamento contínuos do próprio canal para dar lugar à crescente erosão das margens do Valo Grande e consequente assoreamento do porto de Iguape, e o avanço deste rumo às desembocaduras lagunares. Mais especificamente, estimou-se que, até 1911, o Valo Grande despejou cerca de $4.200 .000 \mathrm{~m}^{3}$ de areia erodida de suas margens no Mar Pequeno. Essa grande descarga de sedimentos acabou contribuindo para a formação de grandes depósitos submersos na laguna, diante da desembocadura do canal artificial, onde as correntes de maré não tiveram fluxo competente para movê-los, originando assim a formação de ilhas.

Alguns autores observaram o final de um período de intensa erosão das margens do Valo Grande e assoreamento do Mar Pequeno a partir do ano de 1911, através da análise de mapas e relatos sobre a época. No fim do século XIX, o canal já superava 100m de largura e 10m de profundidade (Geobrás 1966). Em 1978, foi fechado pela construção de uma barragem com a finalidade de evitar a continuação do processo erosivo. A construção interferiu diretamente nas características químicas do sistema, aumentando a salinidade da laguna. A barragem durou até 1983, quando foi rompida devido às enchentes, sendo parcialmente reconstruída posteriormente. Em 1995, não suportando o processo contínuo de deposição sedimentar e as enchentes, foi reaberta e o fluxo proveniente do rio Ribeira que atravessa o canal e desemboca no Mar Pequeno continua, até os dias de hoje, modificando as características geomorfológicas e ecológicas da região.

De maneira geral, a abertura do Valo Grande contribuiu com a aceleração da formação da ilha Comprida pelo aumento das velocidades de correntes de maré vazante associadas aos sedimentos trazidos pelo rio Ribeira de Iguape. Porém, a erosão das margens do Valo Grande, associada à perda de energia das correntes de maré causada pelo assoreamento dos canais pelo aporte sedimentar do rio Ribeira, tenderia a equilibrar as condições hidrodinâmicas locais, diminuindo a influência do canal artificial no crescimento da ilha (Freitas 2005).

De acordo com Saito (2002), toda a região sofre atualmente um forte processo de assoreamento, evidenciado pelo crescimento de feições sedimentares e deposição de sedimentos finos, corroboradas por observação das altas taxas de sedimentação em seu estudo. Há também um estudo feito por Alves (2009) que mostrou através de análises de granulometria e suscetibilidade magnética de testemunhos coletados próximo à desembocadura do Valo Grande, o desenvolvimento de um delta intralagunar no sistema.

\section{Metodologia}

O primeiro passo do trabalho foi a digitalização dos dados dos perfis batimétricos presentes na carta topográfica da segunda edição do relatório "Exploração do Rio Ribeira de Iguape”, publicado em 1914 pela Comissão Geográfica e Geológica do Estado de São Paulo.

Esses perfis transversais, segundo o relatório citado, foram obtidos com uma corda de linho assinalada de metro em metro, sendo as profundidades de até $5 \mathrm{~m}$ tomadas com uma vara marcada de decímetro em decímetro, e, quando maior, servia-se então de uma corda marcada em decímetros e com um peso de $5 \mathrm{~kg}$, suficiente para manter a perpendicularidade.

Posteriormente, esses dados foram convertidos em coordenadas compatíveis com as dos perfis batimétricos obtidos em campo no ano de 2008. Essa conversão foi necessária para a estimativa da variação das seções do canal do Valo Grande ao longo do século $\mathrm{XX}$.

Para obtenção dos dados batimétricos atuais em campo, foi necessário o georreferenciamento da carta topográfica presente no relatório da Comissão Geográfica e Geológica do Estado de São Paulo para obter as coordenadas de cada seção batimétrica. Utilizou-se o software Global Mapper ${ }^{\circledR}$ como instrumento de georreferenciamento, e o mapa topográfico do município de Iguape do IBGE (1973) (figura 2) como base de referência para obter as coordenadas utilizadas na localização da coleta de dados. 

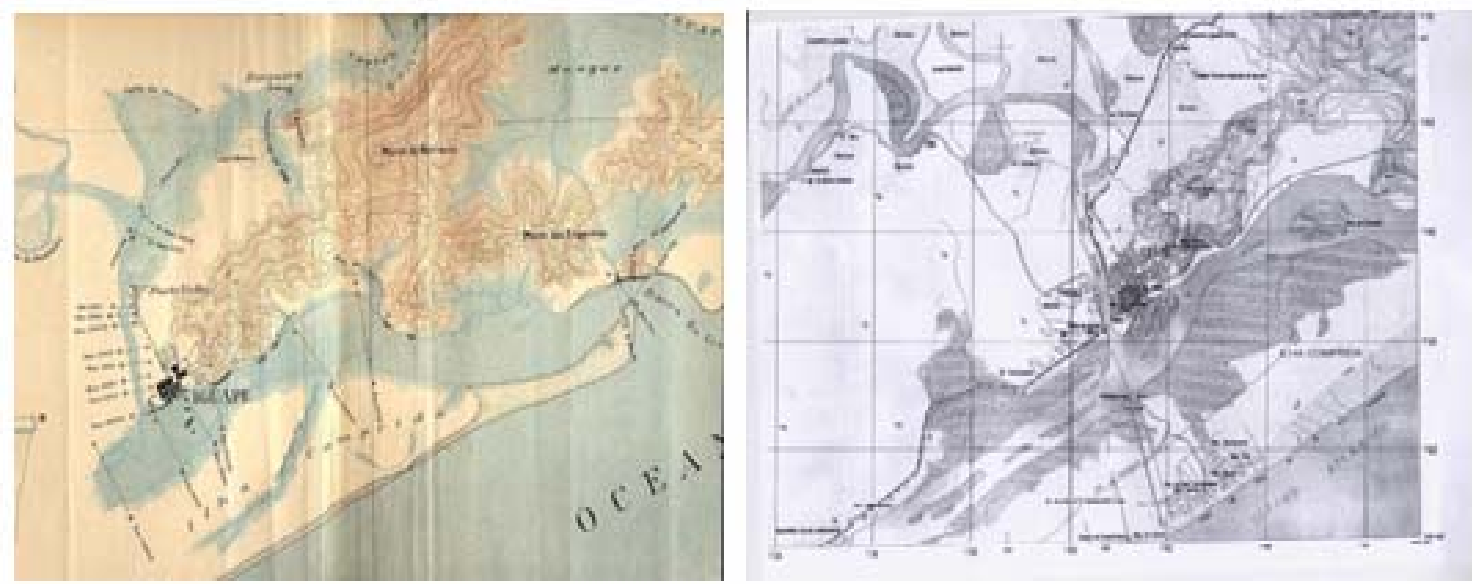

Figura 2: Mapas topográficos da região do canal do Valo Grande em 1908 (à esquerda) (Comissão geográfica e geológica do estado de São Paulo, 1914) e em 1973 (à direita) (IBGE, 1973)

Esse método foi necessário para converter as coordenadas do mapa topográfico de 1908 em coordenadas compatíveis com o GPS do ecobatímetro e equipamentos da embarcação utilizados em campo, pois no ano de 1908, quando o mapa foi confeccionado, o meridiano de referência era o do Rio de Janeiro.

Após a obtenção das coordenadas locais análogas àquelas dos perfis de batimetria obtidos em 1907, foi realizado levantamento batimétrico específico da região, em 2008. Neste levantamento, foi utilizada uma ecossonda Furuno, com transdutor de $50 \mathrm{kHz}$, referenciada com sistema DGPS. O tratamento dos dados obtidos no levantamento em campo foi efetivado com correção de maré e remoção de spikes (pontos espúrios).

Para realizar o estudo comparativo da variação geomorfológica da região e da topografia de fundo, foi necessário estabelecer como base um mapa vetorial a partir da digitalização de uma linha de costa para formulação de uma imagem tridimensional com os dados obtidos em campo. Essa linha de costa foi elaborada com o uso de uma aerofotografia de 2001, obtida no Instituto Florestal de São Paulo, a partir de um levantamento executado para a Secretaria do Meio Ambiente.

O processo de vetorização consiste em representar dados geográficos na forma de pontos, linhas e polígonos. As imagens utilizadas neste trabalho, obtidas por sensoriamento remoto, os mapas topográficos digitalizados e a foto aérea, consistem em informações representadas por um conjunto de células, chamadas pixels, que variam de valores entre 0 e 255 níveis de cinza.

Dessa forma, foi realizada a digitalização das linhas de costa a partir das imagens de satélite do Instituto Nacional de Pesquisas Espaciais (INPE), da foto aérea de 2001, dos mapas topográficos do IBGE e do relatório da Comissão Geográfica e Geológica do Estado de São Paulo, para análise da evolução geomorfológica do sistema entre os anos de 1908 e 2008. As imagens de satélite utilizadas no estudo constituem-se de passagem do sensor TM do Landsat
5, obtidas no banco de dados da Divisão de Geração de Imagens (DGI) do INPE e possuem resolução de 30m. Estas foram utilizadas neste trabalho para representar a região nos anos de 1987, 1990, 1991, 1992, 1993, 1995, 1997, 1999, 2003, 2007 e 2008.

Para que o trabalho de digitalização fosse possível, foi necessária a manutenção das imagens georrefenciando-as através do software Envi ${ }^{\circledR}$, utilizando como base a imagem digitalizada e georreferenciada (originalmente em unidades UTM, fuso $23 \mathrm{~S}$ e datum SAD 69) da foto aérea de 2001, normalizando-as geograficamente (datum, elipsóide e coordenadas). Isso porque, segundo Araújo (2010), as imagens Landsat adquiridas no INPE não são acuradas geometricamente; ou seja, não servem para ser utilizadas em análises multitemporais.

A figura 3 mostra o processo de georreferenciamento e um dos pontos de controle que foram utilizados neste procedimento, marcado tanto na foto georreferenciada usada como base (lado esquerdo), quanto no mapa topográfico a ser geoprocessado pelo software (lado direito).

Após o georreferenciamento das imagens, foram feitas as digitalizações das linhas de costa de cada imagem de satélite, da foto aérea e dos mapas topográficos utilizando o pacote IDRISI $^{\circledR}$. Os dados vetoriais obtidos na digitalização foram convertidos para o formato .bln de forma que fosse possível plotálos no programa Surfer ${ }^{\circledR}$. Além de ter sido utilizado visando à confecção de mapas na análise temporal da linha de costa, o Surfer foi utilizado como ferramenta para a construção de um modelo digital de terreno baseado nos dados batimétricos obtidos em campo no ano de 2008.

A construção do modelo digital de terreno constituiuse basicamente na elaboração de uma malha com os dados de batimetria devidamente corrigidos, de acordo com os dados de maré da região, interpolados por krigagem ordinária, e com o mapa vetorial da linha de costa elaborado a partir da foto aérea de 2001, com resolução de $1 \mathrm{~m}$. 
Antropoceno - Tecnógeno

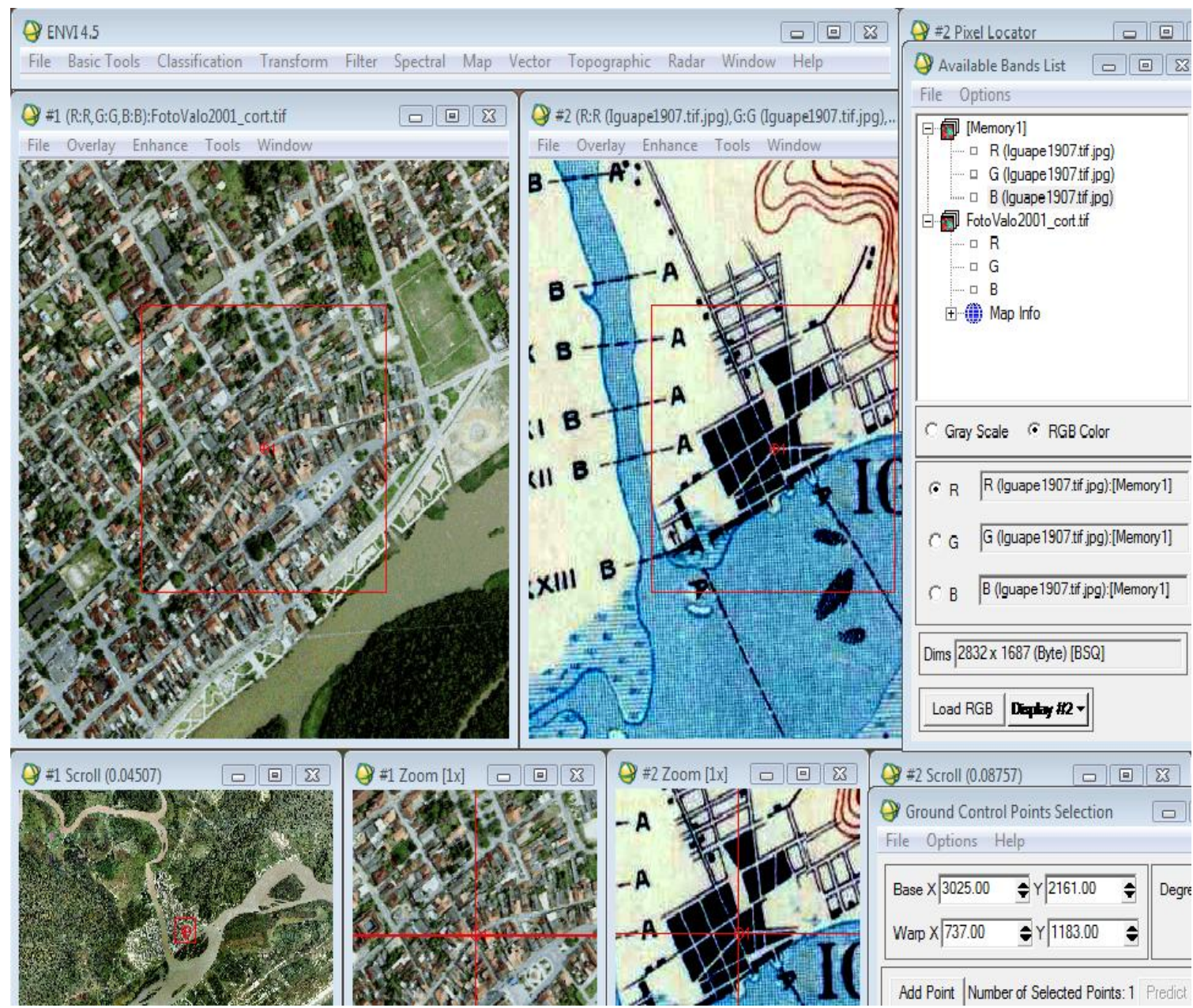

Figura 3: Parte do processo de georreferenciamento do mapa topográfico de 1914 do relatório da Comissão Geográfica e Geológica do Estado de São Paulo

Cálculos da variação da área de cada perfil batimétrico foram realizados no programa Excel $^{\circledR}$ a partir da formulação de gráficos de profundidade por distância, em metros, entre uma profundidade e outra.

Como os dados do ano de 2008 foram obtidos na forma de profundidade versus coordenadas, estes foram convertidos para profundidade versus distância, para que fosse possível a comparação com as seções dos anos anteriores.

Somente a seção XXVIII não foi passível de ser refeita no levantamento de 2008, devido à presença de um banco de areia no meio do canal, na área correspondente a esta seção.

\section{Resultados e discussão}

Por meio dos mapas vetoriais da linha de costa de cada imagem digital adquirida da região de estudo e a obtenção de um modelo digital de terreno, foi possível observar muitos pontos de variações morfológicas influenciadas por processos de assoreamento e erosão intensos, tanto no Mar Pequeno quanto no canal do Valo Grande.

\subsection{Variação da linha de costa}

A análise dessas mudanças na morfologia do sistema foi abordada de forma qualitativa, não tendo sido especificada a fase de maré em cada uma das imagens de satélite e principalmente na foto aérea de 2001, que foi utilizada como base para a formulação do modelo digital de terreno.

A figura 4 apresenta os mapas vetoriais da linha de costa de cada imagem digital adquirida da região de estudo elaborados no software IDRISI ${ }^{\circledR}$ e exportados para o formato .bln (compatível com o software Surfer ${ }^{(\mathbb{R}}$ ).

A figura 4A representa o canal do Valo Grande em meados de 1908, época em que a erosão das margens do canal já era observada e já existiam preocupações com o assoreamento do porto de Iguape. Podem-se observar na imagem poucos e pequenos bancos de areia perto da desembocadura do Valo Grande.

$\mathrm{Na}$ imagem de 1973 (figura 4B) já se observa a intensificação do assoreamento com o surgimento de várias ilhas e a evolução de algumas já existentes na década de 1920. 
Antropoceno - Tecnógeno
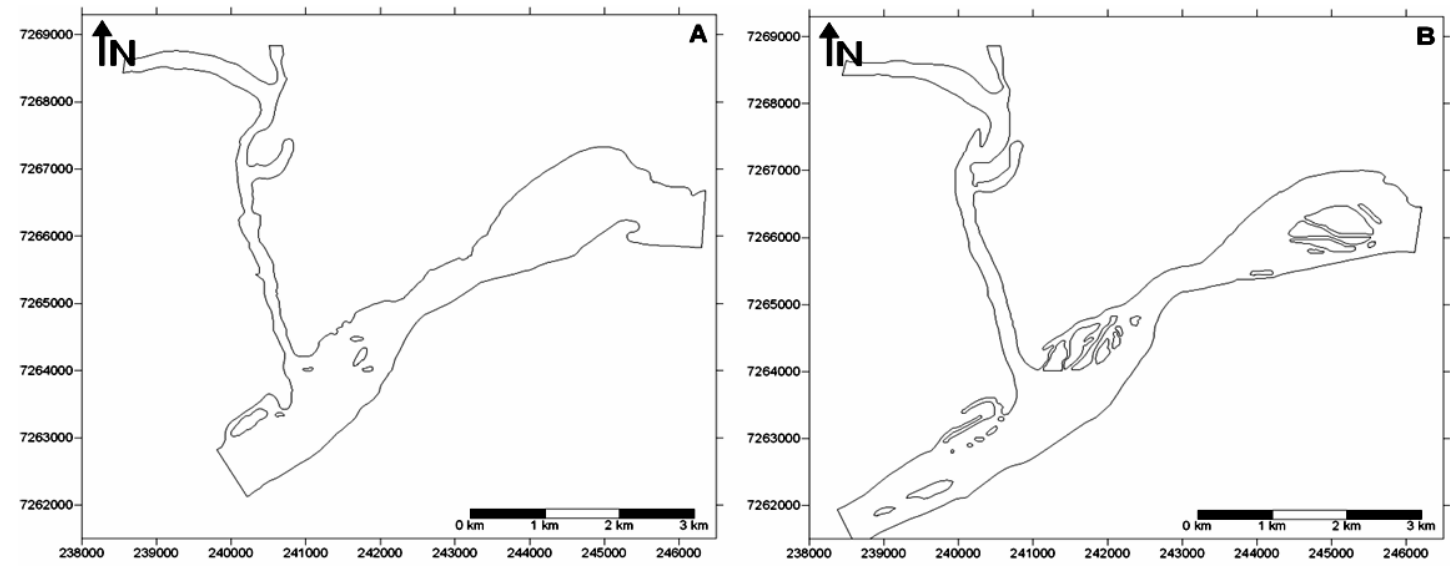

Figura 4: Linha de costa nos anos de 1908 (A), 1973 (B), 1987 (C), 1990 (D), 1991 (E), 1992 (F), 1993 (G), 1995 (H), 1997 (I), 1999 (J), 2001 (K), 2003 (L), 2007 (M), 2008 (N)
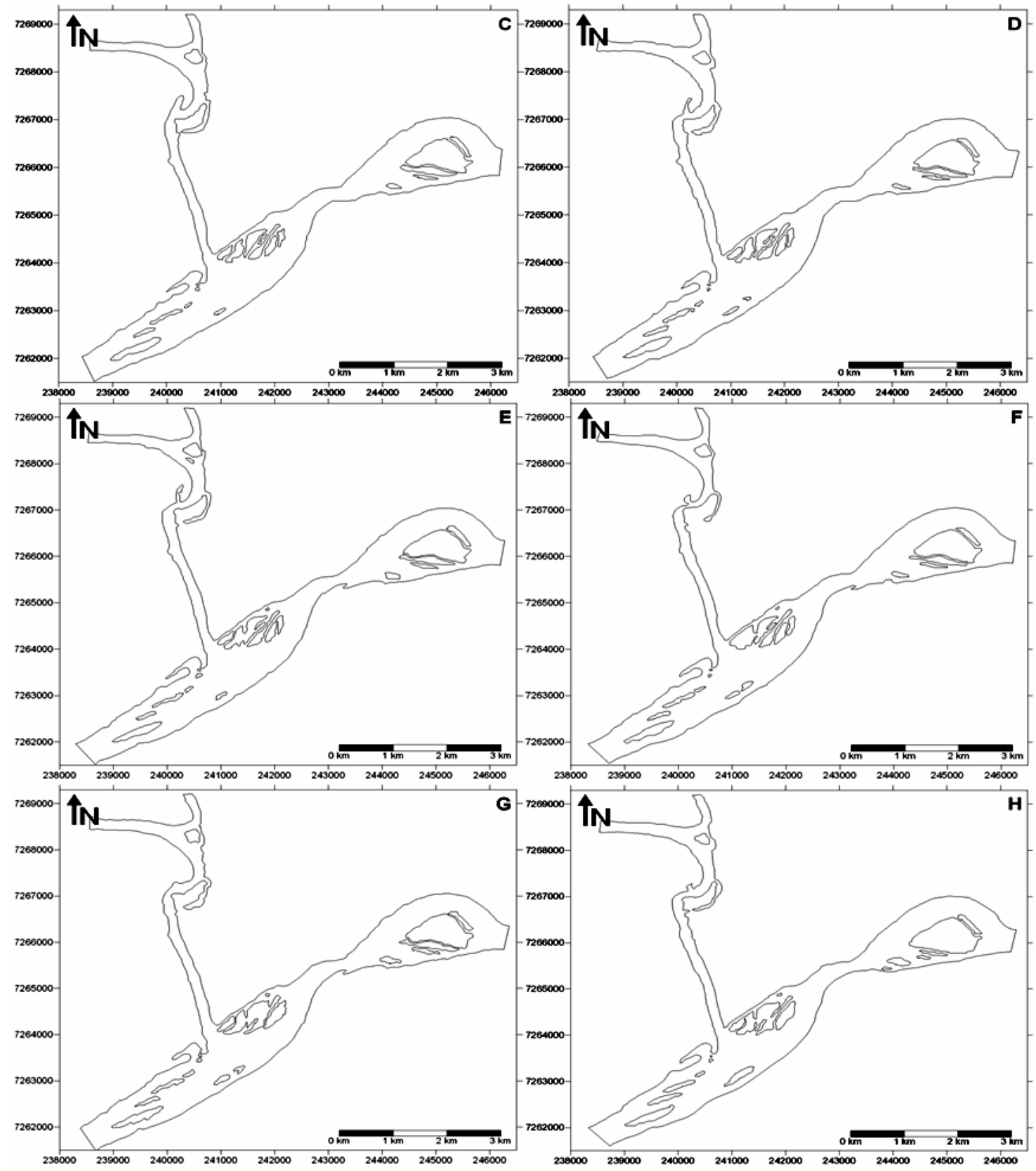

Figura 4: Linha de costa nos anos de 1908 (A), 1973 (B), 1987 (C), 1990 (D), 1991 (E), 1992 (F), 1993 (G), 1995 (H), 1997 (I), 1999 (J), 2001 (K), $2003(\mathrm{~L}), 2007(\mathrm{M}), 2008(\mathrm{~N})$ 
Antropoceno - Tecnógeno
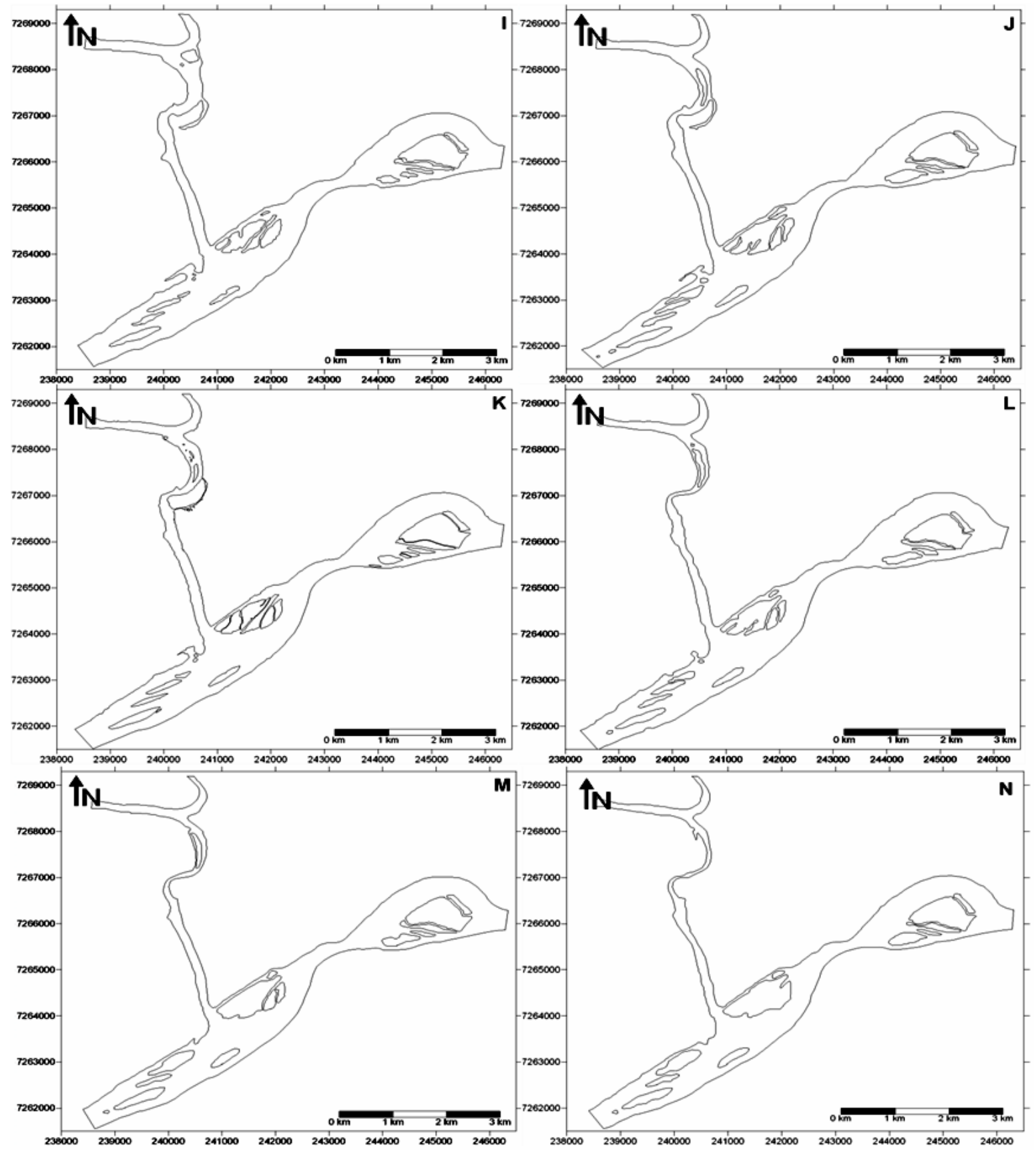

Figura 4: Linha de costa nos anos de 1908 (A), 1973 (B), 1987 (C), 1990 (D), 1991 (E), 1992 (F), 1993 (G), 1995 (H), 1997 (I), 1999 (J), 2001 (K), 2003 (L), 2007 (M), 2008 (N)

A partir do ano de 1987 em diante (figuras 4C a 4N), pode-se observar o desenvolvimento mais expressivo de um delta intralagunar em frente à desembocadura do Valo Grande e a evolução dos bancos de areia já existentes.

$\mathrm{Na}$ figura 5, que apresenta um gráfico comparativo das linhas de costa em 1987 e 2008 para avaliação de sua evolução temporal no Valo Grande, podem-se observar muitos pontos de variações morfológicas influenciadas por um processo de assoreamento intenso. Isso é evidente através do aumento de áreas emersas de pequenas ilhas com deposição sedimentar lateral.

Freitas (2005) fez comparações da linha de costa, na região da desembocadura do Valo Grande, entre os anos de 1981 e 2001, concluindo que um banco arenoso, na margem esquerda da desembocadura do canal, cresce em forma de pontal. Além disso, observou-se um assoreamento significativo do Baixio do Caranguejo e no conjunto de ilhas sedimentares associadas.

Há também a junção de um aglomerado de ilhas adjacentes à desembocadura do canal, opostas ao Baixio do Caranguejo, causada pela deposição sedimentar nos canais internos. A progradação da linha de costa e o desaparecimento de alguns "braços" do canal também podem ser observados. No entanto, o processo erosivo é pouco notado ao longo desses anos e age em poucos trechos. 
Antropoceno - Tecnógeno

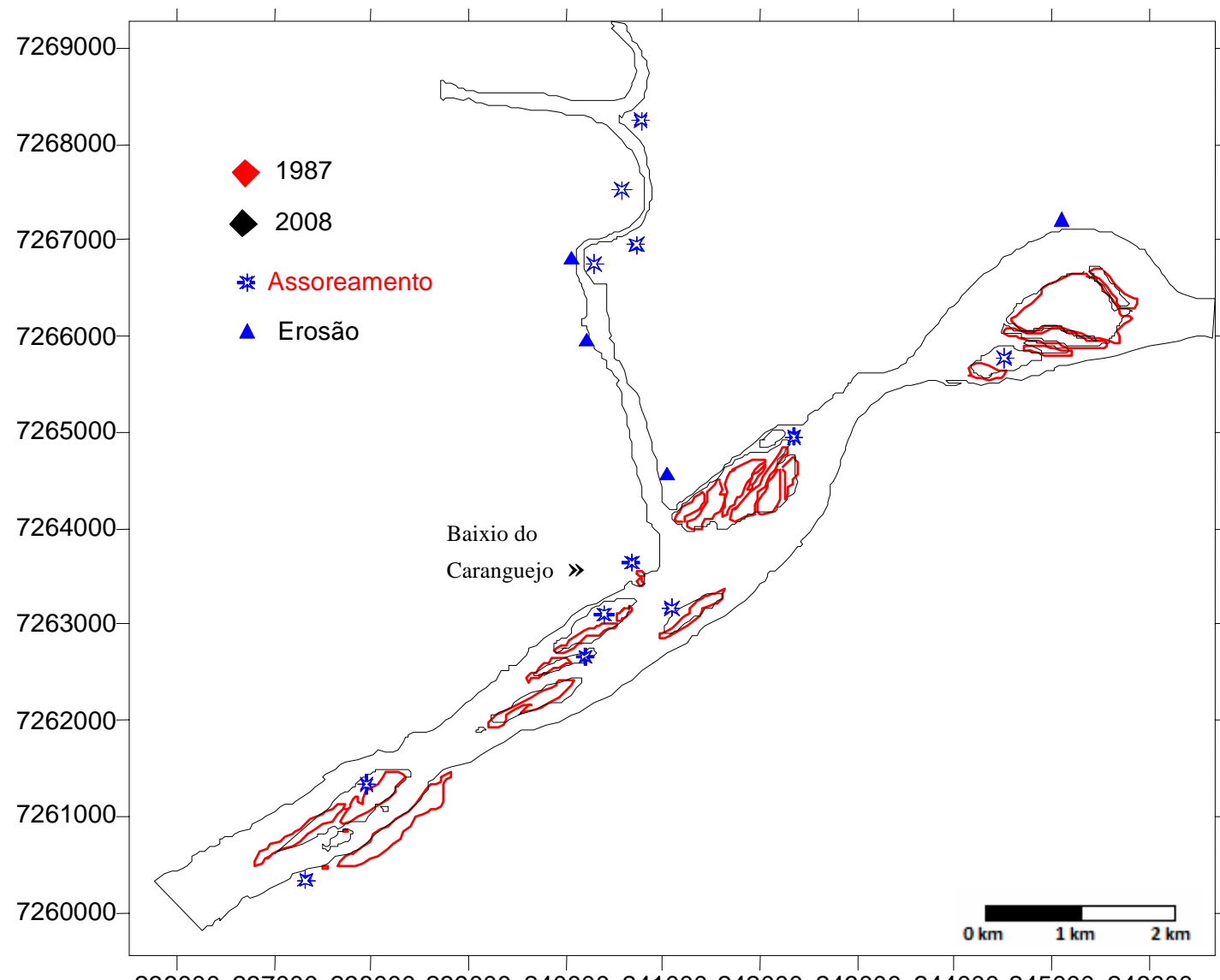

Figura 5: Evolução da linha de costa entre os anos de 1987 e 2008 com indicações dos processos de assoreamento e erosão

\subsection{Modelo Digital de Terreno}

A figura 6 representa o Modelo Digital de Terreno (MDT), apresentando a topografia de fundo da desembocadura do canal artificial do Valo Grande no ano de 2008. Valores relativamente altos de profundidade podem ser observados na parte interior do canal artificial. Já, perto da boca do canal, a profundidade começa a diminuir, indicando um forte processo de sedimentação no encontro das águas do canal artificial com as águas do Mar Pequeno.

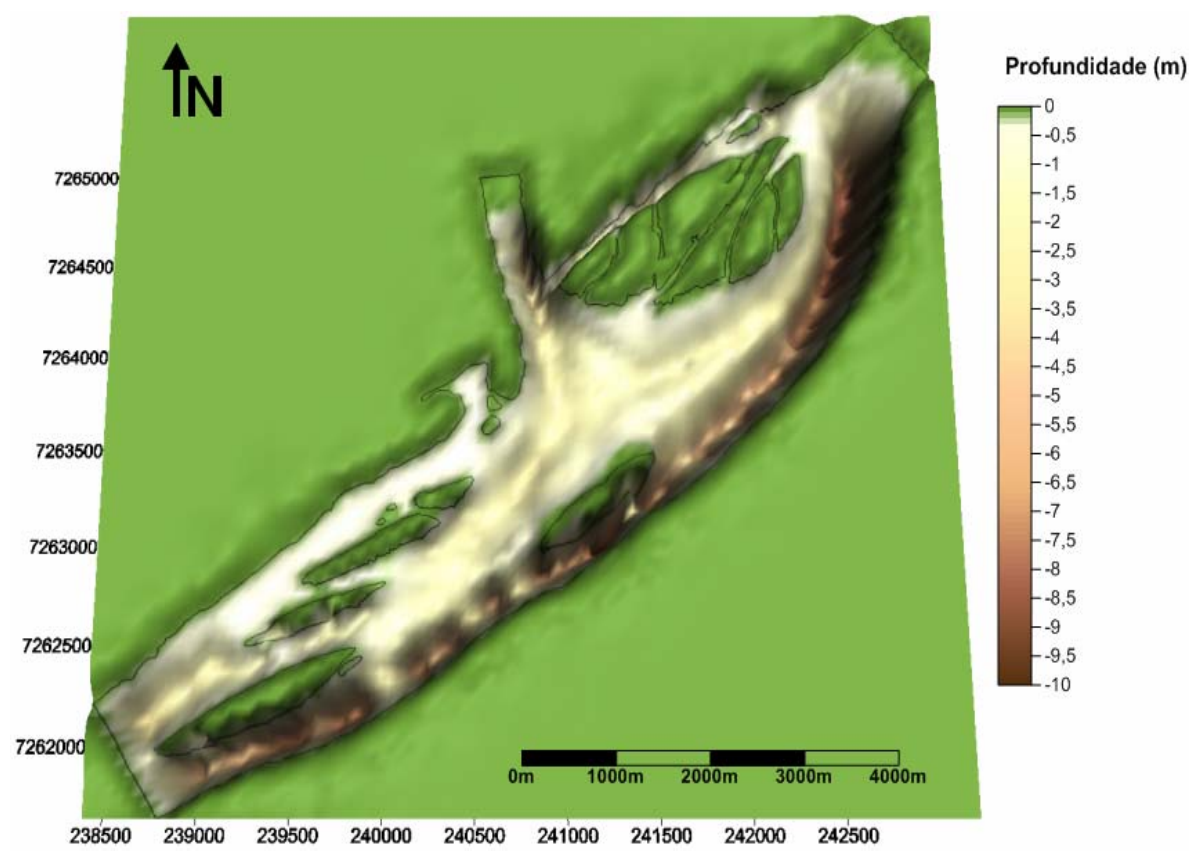

Figura 6: Modelo Digital de Terreno para a região do Valo Grande no ano de 2008 
A existência de maiores profundidades no interior do canal artificial e o forte processo de erosão em suas margens podem ser explicados pelo fato de se tratar de um corpo de água com fluxos intensos, uma vez que $70 \%$ do fluxo do rio Ribeira passou a percorrer uma distância muito menor do que seu percurso normal até atingir o mar (Geobrás 1966).

Por outro lado, as águas do Mar Pequeno apresentam menor energia hidrodinâmica, influenciada pelas inversões do fluxo de maré, não apresentando capacidade para mobilizar a descarga de sedimentos proveniente do canal artificial, favorecendo assim a formação de bancos de areia, ilhas e um delta intralagunar em frente à desembocadura. Por sua vez, a formação dessas ilhas e do delta serviu como barreira para a descarga contínua de sedimentos, permitindo a formação de um canal principal de fluxo, com profundidades significantes, rente às margens da ilha Comprida.

\subsection{Variação das seções batimétricas}

A Figura 7 representa o mapa indicando a localização dos dados de batimetria obtidos no levantamento de 2008. Este serviria como base para a elaboração do modelo 3D do canal, utilizando o mesmo software, do qual seriam extraídas as seções correspondentes àquelas presentes no mapa de 1908 (figura 8). Porém, como os perfis batimétricos estão muito distantes uns dos outros, não foi possível fazer uma interpolação coerente dos dados. A partir daí, optou-se por trabalhar diretamente com as seções dos perfis obtidos em campo, uma vez que as posições são aproximadamente as mesmas dos perfis antigos.

A tabela 1 mostra a largura aproximada, em metros, em cada ano para os perfis batimétricos do Valo Grande. Nem todos os perfis foram medidos no ano de 1891, pois como se pode verificar através da tabela, entre essas seções, só foram obtidos dados batimétricos nos perfis XXIX e XXXIII neste ano.

A utilização da largura do canal no ano de 2001 para a comparação deu-se pelo fato de que esta foi obtida numa base georreferenciada mais confiável através do software Global Mapper. Essa base consistiu num mapa vetorial do canal, desenhado a partir da foto aérea.

A figura 9 mostra os perfis batimétricos de cada seção nos anos de 1907 e 2008, sendo que os perfis 3 e 7 também apresentam os dados de profundidade do ano de 1891.

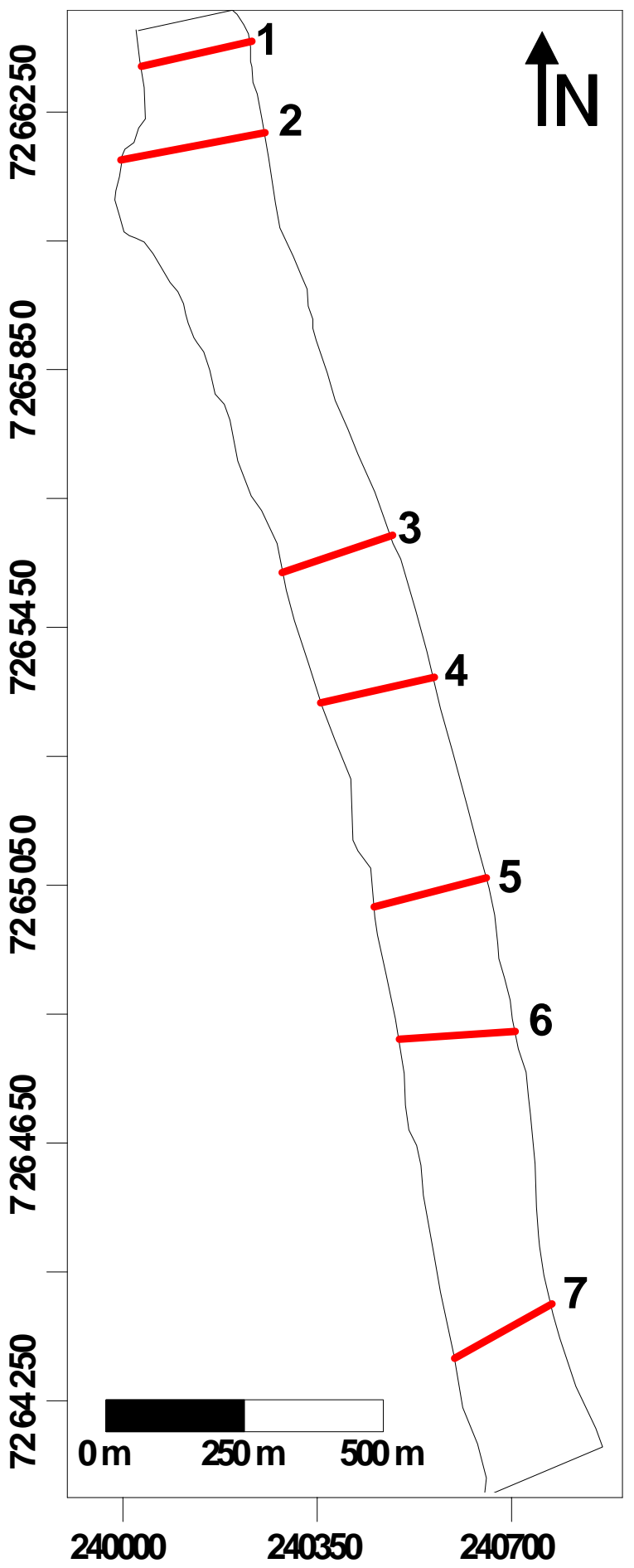

Figura 7: Trecho do Valo Grande (Iguape, SP) indicando a localização dos dados de batimetria obtidos no levantamento de 2008 


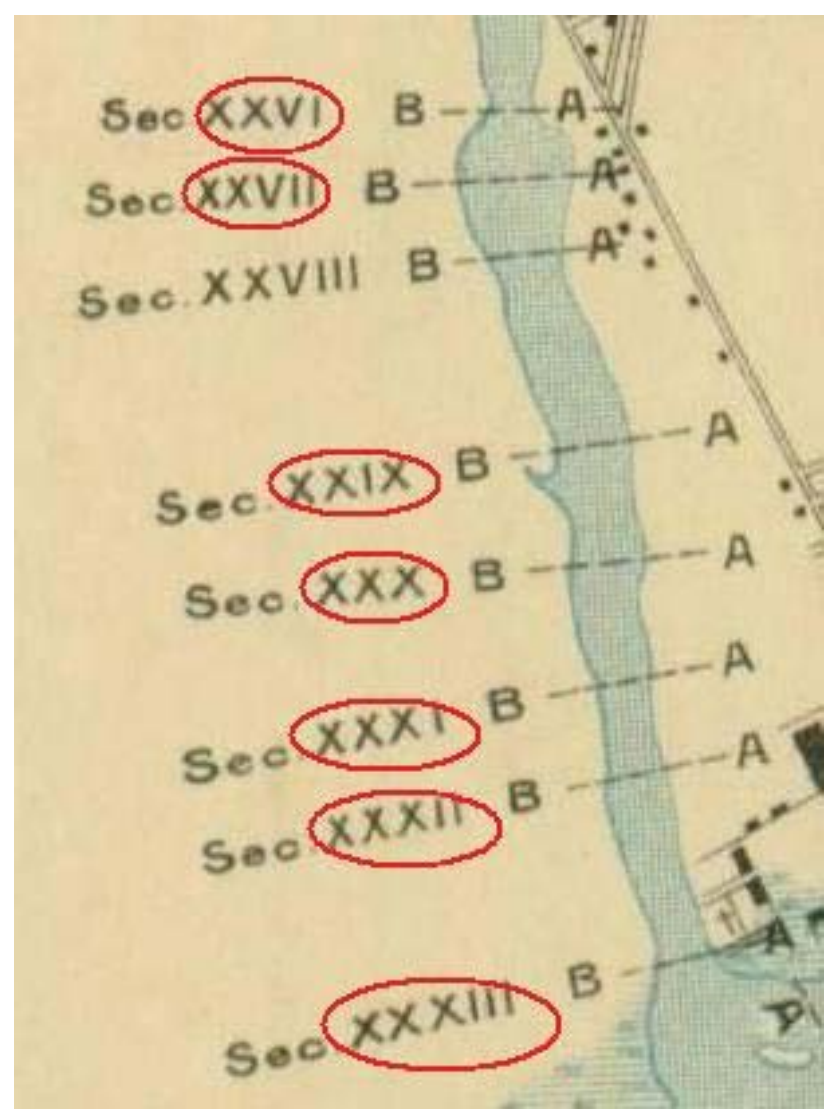

Figura 8: Parte do mapa topográfico de 1908 da região do Valo Grande (Iguape, SP), indicando os perfis batimétricos utilizados para comparação de largura e área transversal

Tabela 1: Largura (m) dos perfis batimétricos do Valo Grande nos anos 2001, 1907 e 1891

\begin{tabular}{c|ccc}
\hline Perfil & $\mathbf{2 0 0 1}$ & $\mathbf{1 9 0 7}$ & $\mathbf{1 8 9 1}$ \\
\hline 1 (XXVI) & 203 & 131 & -- \\
2 (XXVII) & 270 & 294 & -- \\
3 (XXIX) & 207 & 168 & 124 \\
4 (XXX) & 204 & 135 & -- \\
5 (XXXI) & 195 & 132 & -- \\
6 (XXXII) & 224 & 149 & -- \\
7 (XXXIII) & 207 & 149 & 144 \\
\hline
\end{tabular}

A tabela 2 apresenta os valores das áreas de cada seção nos três anos estudados, mostrando uma tendência à diminuição do volume do canal.

Tabela 2: Área de cada seção em m²

\begin{tabular}{cccc}
\hline \multirow{2}{*}{ Perfil } & \multicolumn{3}{c}{ Ano } \\
\cline { 2 - 4 } & $\mathbf{1 8 9 1}$ & $\mathbf{1 9 0 7}$ & $\mathbf{2 0 0 8}$ \\
\hline 1 (XXVI) & - & 1304,8 & 1219,8 \\
2 (XXVII) & $\overline{-}$ & 2061,1 & 2118,8 \\
3 (XXIX) & 455,6 & 1125,4 & 622,4 \\
4 (XXX) & - & 1221,8 & 584,7 \\
5 (XXXI) & - & 1274,0 & 616,7 \\
(XXXII) & - & 1198,3 & 649,9 \\
7 (XXXIII) & $6 \overline{83,3}$ & 1267,0 & 741,0 \\
\hline
\end{tabular}

A partir da comparação dos gráficos dos perfis e da variação da área de cada seção, pode-se perceber que nesses 100 anos o canal continuou sofrendo um processo de erosão em suas margens, porém não tão intenso quanto no período anterior a 1900. Além disso, foi possível observar que as profundidades diminuíram provavelmente devido à estabilidade do seu fluxo e ao próprio processo de formação do delta intralagunar, havendo assim uma tendência de diminuição da seção do canal nas áreas mais próximas à desembocadura do Valo Grande.

\section{Conclusões}

A abertura do Valo Grande, cuja finalidade era facilitar o transporte fluvial do vale da Ribeira até o mar, acabou provocando o assoreamento do porto de Iguape e dificultando a navegação no Mar Pequeno, que hoje em dia só é possível em determinados períodos de maré enchente e com conhecimento prévio da topografia da região.

Pode-se afirmar com as análises feitas neste estudo que, ao longo dos anos de 1914 a 2008, alguns bancos de areia que antes não existiam começaram a se desenvolver perto da desembocadura do Valo Grande, o que indica intenso processo de assoreamento ainda presente no Mar Pequeno.

Além disso, é importante destacar as evidências do forte processo erosivo nas margens do canal do Valo Grande pela grande diferença da largura e profundidade do canal atual em relação às medidas feitas no início do século passado.

De acordo com os gráficos da profundidade, e dos cálculos das áreas de cada seção, pode-se perceber que apesar da constante erosão das margens do canal, exceto em uma das seções (seção 2/XXVII), houve uma diminuição da área de cada seção, principalmente nas seções mais próximas à desembocadura do canal, o que pode explicar a formação de um delta intralagunar antropogênico. Isso indica que o fluxo do canal diminui consideravelmente, perto do Mar Pequeno, possibilitando assim a deposição de sedimentos.

A evidente evolução geomorfológica, que ocorre em um intervalo de tempo geológico considerado pequeno, chama a atenção para necessidade de estudos regulares e frequentes na região da desembocadura do canal artificial.

\section{Agradecimentos}

Meus agradecimentos a todos os funcionários, professores e colegas do Instituto Oceanográfico e aos técnicos do Laboratório de Informática Geológica do Instituto de Geociências da Universidade de São Paulo. 

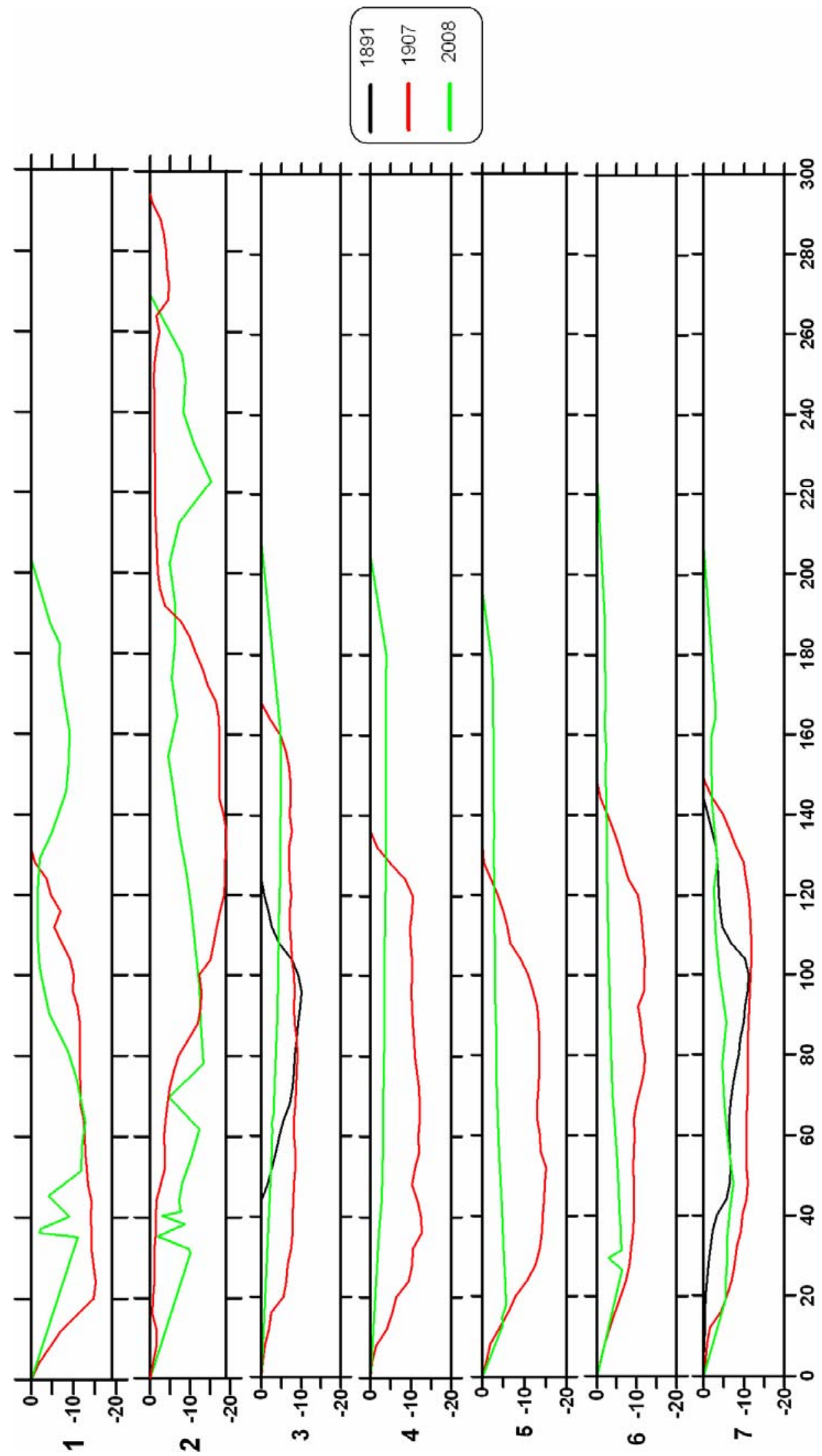

Figura 9: Perfil batimétrico de cada seção nos anos de 1891 (preto), 1907 (vermelho) e 2008 (verde) 


\section{Referências}

Alves D.P.V. 2009. O efeito da abertura do Valo Grande na sedimentação do Sistema Estuarino-Lagunar de CananéiaIguape. Monografia de bacharelado. Instituto Oceanográfico, Universidade de São Paulo, Brasil. 37p.

Araújo C.A.S. 2010. Aplicações de técnicas de sensoriamento remoto na análise multitemporal do ecossistema manguezal na Baixada Santista, SP. Dissertação de mestrado. Instituto Oceanográfico, Universidade de São Paulo, Brasil. 113p.

Bonetti Filho J., Conti L.A., Furtado V.V. 1996. Suspended sediment concentration variability and its relation to tidal currents in microtidal system. An. Acad. Bras de Ciên., 68(3):485-494.

Campos G. de. 1896. Canal de Iguape I, II, III, IV, V, VI. In: O Estado de São Paulo, 01, 03, 04, 06, 10 e 30/07/1896, respectivamente.

Commissão Geographica e Geologica do estado de S. Paulo. 1914. Exploração do Rio Ribeira de Iguape. $2^{\mathrm{a}}$ ed. São Paulo: Typographia Brazil de Rothschild. 34p.

Freitas R.C. 2005. Evolução recente das margens dos canais lagunares e topografia de fundo do sistema Cananéia-Iguape/SP. Dissertação de mestrado. Instituto Oceanográfico da Universidade de São Paulo. 196p.

Geobrás S/A Engenharia e Fundações. 1966. Complexo Valo Grande, Mar Pequeno e Rio Ribeira de Iguape. Relatório. 2 vols., São Paulo, DAEE.

Galloway W.E. 1975. Processes framework for describing the morphologic and stratigraphic evolution of deltaic depositional systems. In: Deltas, Models for Exploration. p.87-98. Houston Ged. Soc. Houston TX.

Kjerfve B., Magill K.E. 1989 Geographic and hydrodynamic characteristics of shallow coastal lagoons. Mar.Gel., Amsterdam, v.88, p.187-199.

Saito R.T. 2002. Radionuclídios (Pb-210, Ra-226; Po-210 e Cs-137) no sistema costeiro Cananéia-Iguape: Estudos Ambientais. 163f. Tese de Doutorado- Instituto de Pesquisas Energéticas e Nucleares, Universidade de São Paulo, São Paulo.

Silva C.G., Patchineelam S.M., Neto J.A.B., Ponzi V.R.A. 2004. Ambientes de sedimentação Costeira e Processos Morfodinâmicos Atuantes na Linha de Costa. In: Batista Neto J.A., Ponzi V.R.A., Sichel S.E. (Org). Introdução à Geologia Marinha. Rio de Janeiro. Interciência: 2004. p.175-218.

Teles A.P.S.S. 1997. A evolução geológica quaternária e a influência do Valo Grande na dinâmica sedimentar da área de Iguape, São Paulo. 178f. Dissertação de Mestrado - Instituto Oceanográfico, Universidade de São Paulo, São Paulo

Recebido 29 de novembro de 2013 Aceito 05 de julho de 2014 